\title{
Roles of Proliferation and Angiogenesis in Locally Aggressive Biologic Behavior of Ameloblastoma versus Ameloblastic Fibroma
}

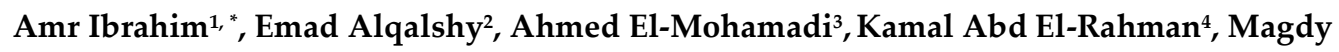 \\ Alazzazi $^{5}$
}

\begin{abstract}
1 Lecturer; Oral and Dental Pathology Department, Faculty of Dental Medicine (Boys-Cairo), AL- Azhar University. Lecturer; Basic Dental Sciences Department, Faculty of Dentistry, Deraya University, New Miya, Minya, Egypt; amr.mohamed@deraya.edu.eg

2 Lecturer; Oral and Dental Pathology Department, Faculty of Dental Medicine (Boys-Cairo), AL- Azhar University, Egypt; emadalqalshy.209@azhar.edu.eg 3 Lecturer; Oral and Dental Pathology Department, Faculty of Dental Medicine (Boys-Cairo), AL- Azhar University, Egypt; Dr.ahmedshokry1@gmail.com 4 Assistant Professor, Oral and Dental Pathology Department, Faculty of Dental Medicine (Boys-Cairo), AL- Azhar University, Egypt; drkamal96@yahoo.com 5 Assistant Professor; Oral Biology Department, Faculty of Dental Medicine (Boys-Cairo), AL- Azhar University, Egypt. Assistant Professor of Oral Biology, College of Dentistry, The Islamic University, Najaf, Iraq; magdyelabasiry@gmail.com

* Correspondence: amr.mohamed@deraya.edu.eg; Tel.: +20-01017577817
\end{abstract}

\begin{abstract}
Background: The present study was carried out to evaluate the roles of proliferation and angiogenesis in locally aggressive biologic behavior of ameloblastoma versus ameloblastic fibroma; Methods: 30 formalin-fixed paraffin embedded blocks ( 15 cases of ameloblastoma \& 15 cases of ameloblastic fibroma) were used. To evaluate the proliferation, the tissue sections were stained with AgNORs stain. CD105 was used as immunohistochemical marker of angiogenesis. Quantitative evaluations of AgNORs were performed. The mean vascular density was evaluated as a measure for CD105 protein expression by using image analyzer computer system; Results: The mean number of AgNORs dots per nucleus was significantly higher in ameloblastoma as compared to ameloblastic fibroma. Also, the protein level of CD105 showed positive expression and wide distribution that the mean vascular density was significantly higher in ameloblastoma as compared to ameloblastic fibroma; Conclusion: Quantitative evaluation of AgNORs stain \& the mean vascular density utilizing CD105 protein expression may reflect a higher proliferative activity and a more locally aggressive biologic behavior of ameloblastoma when compared to ameloblastic fibroma, that other factors may be involved in biologic behavior of ameloblastic fibroma.
\end{abstract}

Keywords: Proliferation; Angiogenesis; Biologic Behavior; Ameloblastoma; Ameloblastic Fibroma 


\section{Introduction}

Odontogenic tumors are rare lesions that arise from odontogenesis-related cells and tissues, as well as their remains. These tumors are a diverse category of lesions that include hamartomatous lesions as well as benign and malignant neoplasms [1]. The World Health Organization (WHO) classification, which has been refined, categorized the benign odontogenic tumors into those of odontogenic epithelial origin, mixed (Epithelial-Mesenchymal) origin, \& mesenchymal origin [1]. Ameloblastoma is rare, odontogenic tumors derived from odontogenic epithelium. Ameloblastoma represents about $1 \%$ of all jaw tumors, but it considered to be the second-most common odontogenic tumor, although benign, is known for its locally invasive behavior with a high risk of recurrence [2]. Ameloblastic fibroma is a rare mixed odontogenic tumor which constitutes $2 \%$ of odontogenic tumors. However, some researchers believe that at least some cases of ameloblastic fibroma are hamartomatous and represent the first stage of an odontoma's development. Nonetheless, the neoplastic origin of ameloblastic fibroma appears to be favoured due to high recurrence potential. [3].

Knowledge of The biologic behaviour of pathologic entities that affect the oral cavity, such as odontogenic tumors, is crucial for choosing the optimal treatment approach and defining a prognosis for each patient. Proliferative activity was an important predictor of biologic behavior of pathologic condition and as a potential guide for therapy. Epithelial proliferations have played a significant role in the behavior of odontogenic tumors [4].

Nucleolar organizer regions (NORs) are DNA loops that actively transcribe to ribosomal RNA, which then transcribes to ribosomes and, eventually, to protein. The NORs are linked to non-histonic acidic argyrophilic proteins, which can be seen using the AgNORs technique. In hyperplastic and neoplastic conditions, quantitative assessments of NORs can indicate the degree of cell nucleolar activity [5]. Several studies have confirmed the usefulness of AgNORs in reflecting the biologic behavior and cellular proliferative activity of odontogenic tumors [5-7].

The connective tissue stroma supports epithelial alterations and expansion through angiogenesis since odontogenic epithelial cells lack a vascular system. In neoplasia, a lack of nutrients and oxygen results in cells death due to a lack of neovascularization. The existence of myofibroblasts and blood vessels in the connective tissue stroma is critical for neoplastic growth, and angiogenesis is essential for that proliferation. Angiogenesis is a series of events that results in the development of new blood vessels from pre-existing vessels. Proliferation and endothelial cell migration, proteolytic breakdown of extracellular matrix, capillary formation, loop and lumen development, and micro vessel anastomosis are among the mechanisms studied [8]. Immunohistochemical labelling with monoclonal antibodies to endothelial cell antigens can reveal angiogenic vessels. In contrast to regular endothelial cells markers, CD105 is an ideal angiogenesis marker that identify the quality and quantity of 
newly created capillaries, because it is expressed differently in angiogenesis than in normal endothelial cells (CD31 and CD34) $[9,10]$.

Because angiogenesis reflects the growth potential of odontogenic tumors, measuring mean vascular density can help anticipate the biologic behavior of these lesions [10- 12]. Therefore, the present study was carried out to evaluate the roles of proliferation and angiogenesis in locally aggressive biologic behavior of ameloblastoma versus ameloblastic fibroma.

\section{Materials \& methods}

\subsection{Samples selection}

30 formalin-fixed paraffin embedded blocks (15 cases of ameloblastoma \& 15 cases of ameloblastic fibroma) were used, they were collected from the archives of the Pathology Department, the National Cancer Institute (Cairo University), Oral \& Dental Pathology Departments, Faculty of Dental Medicine, Al-Azhar University and Faculty of Oral \& Dental Medicine, Cairo University. Histological diagnosis as well as any relevant clinical data of selected cases was taken from the accompanying clinical sheet. Tissue sections were cut at $5 \mu \mathrm{m}$ tissues thick and stained with hematoxylin and eosin (H\&E) to confirm the diagnosis and AgNORs stain. AgNORs staining was carried out according to standard staining method [13].

\subsection{Immunohistochemistry}

Immunohistochemistry was used to apply CD 105 antibody to tissue sections in this study. After coating Super-frosted slides with Poly-L-lysine, one section from each block, measuring 3-4 m in thickness, was taken. The CD105 antibody (Dako) was used to react with these sections utilizing the avidin-biotin-peroxidase complex technique. The sections were dried in a hot air oven at $60^{\circ} \mathrm{C}$ for 60 minutes, then dewaxed by immersion in xylene twice for 5 minutes, $100 \%$ and \% percent ethanol for 3 minutes twice each, and washing with distilled water for 2 minutes twice. Proteinase $\mathrm{K}$ was used to retrieve antigen, which was kept at $37^{\circ} \mathrm{C}$ for 30 minutes. Washing with water for 10 minutes was followed by 3 changes of washing with PBS for 2 minutes each. On the slide, 1 to 2 drops of hydrogen peroxidase block were placed, incubated for 10 minutes, and then washed in PBS. This was followed by a 2-3 minute soak in a buffer bath. Primary antibodies were diluted 1:10 according to the manufacturer's recommended dilutions (Dako). On the slides, 2 drops of primary antibody were put and incubated for 1 hour. This was followed by 30 minutes of linker solution application and 2-3 minutes in the buffer bath. After that, the biotinylated secondary antibody reagent (10 minutes) and streptavidin peroxidase reagent (10 minutes) were applied, followed by PBS wash and buffer bath. Finally, a chromogenic substrate solution was applied for 10 minutes before being washed. Prior to assessment, slides were dehydrated by immersing them in $70 \%, 90 \%$, and $100 \%$ ethanol for 5 minutes each, followed by immersion in Xylene for 5 minutes and mounting with DPX [14]. 


\subsection{Staining interpretations}

Quantitative analysis of AgNORs were carried out using a standard light microscope [15]. AgNORs stains appeared as distinct intra-nuclear black dots that were manually counted in 100 nuclei at a magnification of 1000x with oil immersion in all tissue sections investigated. Finally, each case's mean value and standard deviation were calculated.

Under a light microscope, stained sections were interpreted microscopically. Micro vessels were identified as vascular endothelial cells, which were labelled with CD105 and easily identified by brown cytoplasmic staining. Only strong positively stained endothelial cells or cell clusters that were easily differentiated from adjacent micro vessels and other connective tissue elements were regarded unique countable micro vessels, according to Weidner's (Weidner et al., 1993) criteria [16]. Ten separate fields with a high number of vessels were randomly chosen under x100 magnification. At x400 magnification (about $0.18 \mathrm{~mm}^{2}$ field size), micro vasculature were counted in each of ten fields. A twin head microscope was used by two operators to evaluate all of the slides at the same time. Each micro vessel had to be agreed upon by both of them before it was counted. The mean vascular density was computed as the average number of vessels per high-power field, and the results were then documented according to the protocol.

\subsection{Statistical analysis}

Data were represented as mean and standard deviation (SD) values. Student's t-test was used to compare between the studied tissue sections. Spearman's correlation coefficient was used to determine correlations between the two stains. The significance level was set at $p \leq 0.05$. Statistical analysis was performed with IBM SPSS Statistics Version 20 for Windows.

\section{Results}

\subsection{AgNORs stain Results}

Quantitative assessment showed that the mean number of AgNORs dots per nucleus was $1.65 \pm 0.24$ for ameloblastoma (Table 1), located in the nuclei of peripheral cells (columnar ameloblast- like cells) and central cells (stellate reticulum- like cells) of odontogenic epithelial tumor cells (Figure 1, A). Quantitative assessment showed that the mean number of AgNORs dots per nucleus was $1.12 \pm 0.21$ for ameloblastic fibroma (Table 1), located in nuclei of peripheral cells (columnar ameloblast- like cells) and central cells (stellate reticulum- like cells) of neoplastic odontogenic epithelial portion (Figure 1, B). There were significant differences between the mean numbers of AgNORs dots per nucleus in ameloblastoma \& ameloblastic fibroma $\mathrm{P}=0.03$ (Table 1). 


\subsection{Table 1 and Figure $1(A \mathcal{E} B)$}

Table 1. Comparison between AgNORs stain results in ameloblastoma versus ameloblastic fibroma.

\begin{tabular}{cccc}
\hline \multirow{2}{*}{ Tumor type } & \multicolumn{3}{c}{ AgNORs stain results } \\
\cline { 2 - 3 } & mean & $\mathrm{SD}$ & $\mathrm{P}=0.03$ \\
$\mathrm{Ab}$ & 1.65 & 0.24 & \\
\hline $\mathrm{AF}$ & 1.12 & 0.21 & \\
\hline
\end{tabular}

AgNORs

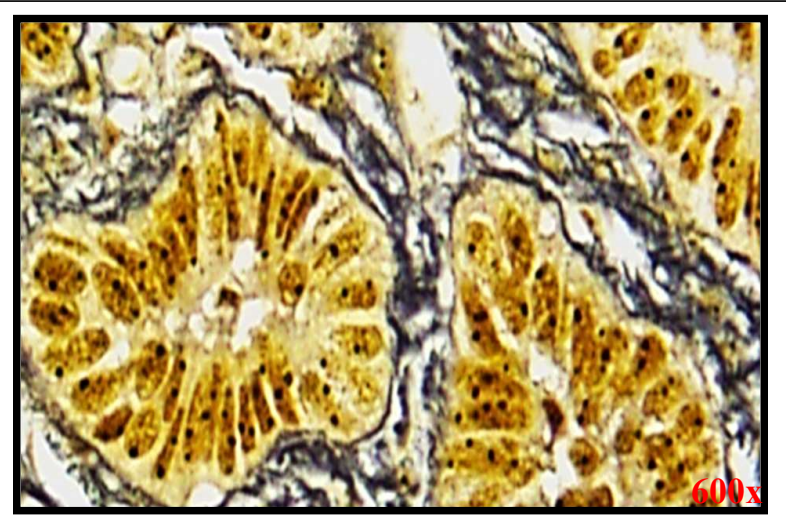

(A)

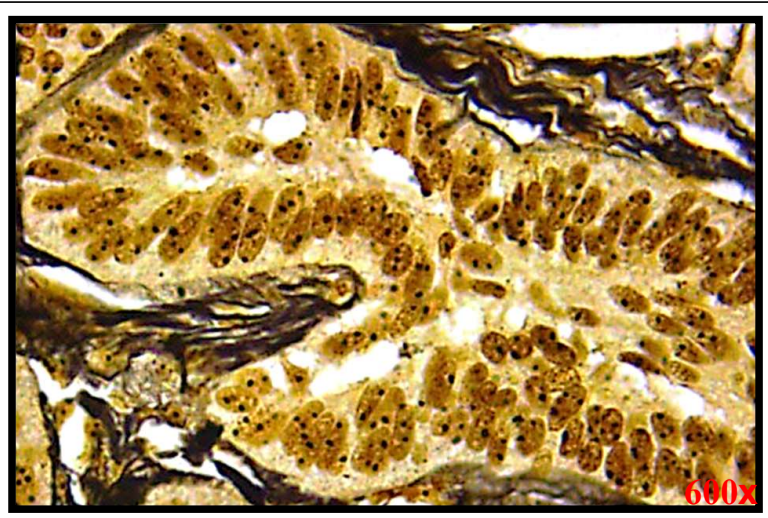

(B)

Figure 1. (A) Photomicrographs of ameloblastoma showing black dots in the nucleus of peripheral columnar ameloblast- like cells and central stellate shaped cells; (B) Photomicrographs of ameloblastic fibroma showing black dots in the nuclei of peripheral columnar ameloblast- like cells and central stellate shaped cells.

\subsection{CD105 protein expression Results}

Immunohistochemical expression of CD105 in ameloblastoma cases, showed positive expression and wide distribution in the endothelial lining of newly formed BVs (Figure 2, A), that the mean vascular density was $27.52 \pm 7.85$ (Table 2) surrounding the odontogenic epithelial tumor cells. Immunohistochemical expression of CD105 in ameloblastic fibroma cases showed positive expression in the endothelial lining of newly formed BVs, the distribution was less prominent (Figure 2, B), that The mean vascular density was $18.2 \pm 3.57$ surrounding the odontogenic epithelial tumor cells. There were significant differences between the mean vascular density in ameloblastoma \& ameloblastic fibroma $\mathrm{P}=0.01$ (Table 2).

\subsection{Table 2 and Figure $2(A \mathcal{E} B)$}

Table 2. Comparison between CD105 protein expression results in ameloblastoma versus ameloblastic fibroma.

\begin{tabular}{ccc}
\hline \multirow{2}{*}{ Tumor type } & \multicolumn{3}{c}{ CD105 results } \\
\cline { 2 - 3 } & mean & $\mathrm{SD}$ \\
$\mathrm{Ab}$ & 27.52 & 7.85 \\
$\mathrm{Ab}$ & 18.2 & 3.57 \\
\hline $\mathrm{AF}$ & & \\
\hline
\end{tabular}


CD105

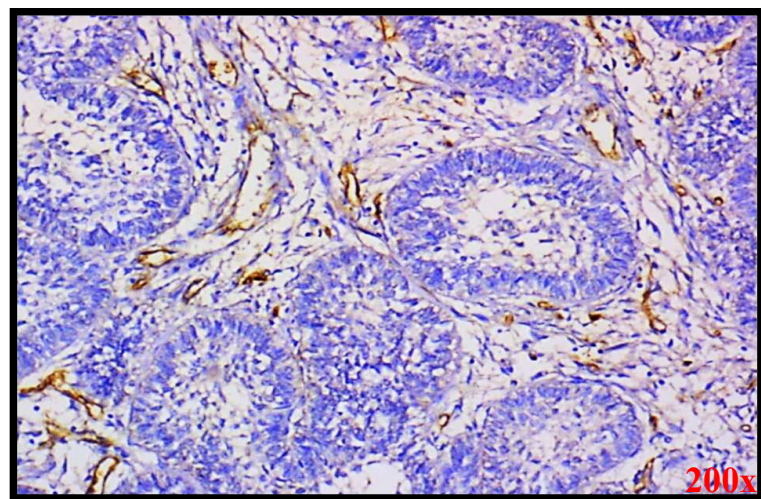

(A)

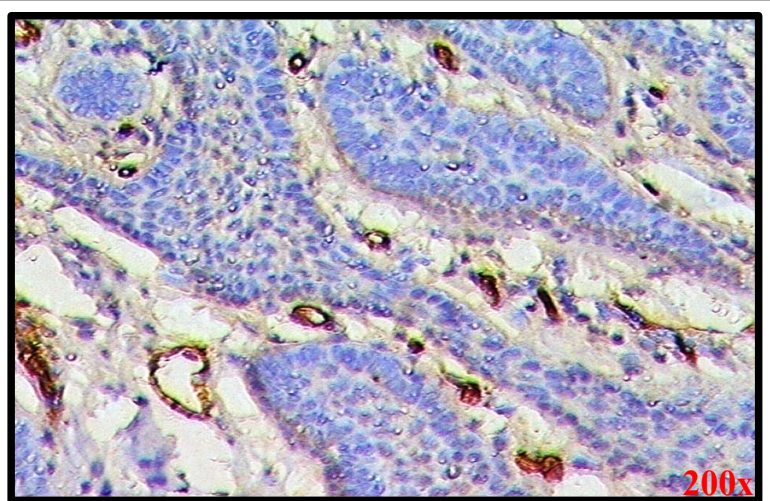

(B)

Figure 2. (A) Photomicrographs of ameloblastoma showing immunohistochemical staining of micro vessels adjacent to epithelial nests; (B) Photomicrographs of ameloblastic fibroma showing Immunohistochemical staining of micro vessels adjacent to epithelial islands.

\section{Discussion}

Odontogenic tumors are a diverse group of lesions with a variety of biologic behaviors. Ameloblastoma is a benign epithelial odontogenic tumor that primarily affects the posterior mandible. Although benign, this tumor has the potential to become aggressive and recur [1]. Ameloblastic fibroma is a mixed odontogenic tumor that frequently affects the posterior mandible. It is a benign, slowly growing, expansile tumor [17]. Some researchers have utilized silver nitrate staining to differentiate the grade of lesions, predict recurrence, and even predict aggressive behaviour. It should also be mentioned that the majority of oral pathology researches has focused on squamous cell carcinoma [18], and salivary gland tumors [18], with only a few studies focusing on odontogenic lesions. Because of the technique's simplicity and repeatability, counting is the most extensively utilized approach for testing AgNORs [19]. The roles of AgNORs and The mean vascular density in locally aggressive biologic behavior of ameloblastoma versus ameloblastic fibroma were obtained in this study.

In the present study, quantitative analysis revealed that the mean number of AgNORs dots in ameloblastoma was significantly higher than in ameloblastic fibroma, indicating that ameloblastoma has a higher proliferative activity. These findings are consistent with prior research, which has found that ameloblastoma has a higher AgNORs index than other benign odontogenic lesions [20], and that this index correlates with the growth potentiality of these lesions. In another similar study, AgNORs were used to assess the proliferative potential of dentigerous cysts, keratocystic odontogenic tumors, conventional ameloblastoma, and unicystic ameloblastoma using quantitative and qualitative criteria. When compared to the other tumors in the study, conventional ameloblastoma had the highest mean number of AgNORs [21].

Interactions between the epithelial and mesenchymal components of developing dental tissues influence odontogenesis. Because odontogenic tumors emerge from 
odontogenesis tissue remnants, these interactions have been thought to play a key role in the production of odontogenic tumors. The connective tissue stroma is critical for epithelial tissue preservation, and modest changes in the epithelium are followed by comparable changes in the stroma, such as angiogenesis [9]. Other endothelial markers have shown less selectivity for tumor vasculature than CD105 [22].

The protein level of CD105 in the current study indicated positive expression, wide distribution, and an increase in the mean vascular density, which was significantly higher in ameloblastoma than in ameloblastic fibroma. The findings of the mean vascular density in this study support that the angiogenesis have an important role in tumor progression, invasiveness and the locally invasive biologic behavior of ameloblastoma, which is comparable to the findings of ameloblastic fibroma. These findings are consistent with Martano et al., [23]. As a result, it's vital to realize that the epithelium in odontogenic tumors induces angiogenesis in connective tissue, and the formation of new blood vessels around the odontogenic epithelium for nutrients and oxygen facilitates tumor growth. Through using Ki- 67 and CD34, Liu et al., [24], evaluated the proliferative activity and biologic behaviour of ameloblastic fibroma in an 8-year-old male rhesus macaque with unilateral enlargement of the left mandible. Their findings demonstrated that the neoplasm's epithelial and ectomesenchymal components exhibited modest proliferation.

\section{Conclusion}

Quantitative evaluation of AgNORs stain (as a tool of proliferation) \& immunohistochemical evaluation of the mean vascular density utilizing CD105 protein expression (as indicator of angiogenesis) may reflect a higher proliferative activity and a more locally aggressive biologic behavior of ameloblastoma when compared to ameloblastic fibroma, that other factors may be involved in biologic behavior of ameloblastic fibroma.

\section{Patents}

Author Contributions: Conceptualization, A.M. and E.A.; methodology, A.M. and E.A.; software, A.M.; validation, A.M. and E.A.; formal analysis, A.M. and E.A.; investigation, A.M. and E.A.; resources, A.M. and E.A.; writing-original draft preparation, A.M. and E.A.; writing-review and editing, A.M. and E.A.; supervision, A.M. and E.A.

Confirmation of Authorship: All authors have read and agreed to submit the manuscript to Diagnostics Journal.

Funding: This research did not receive any specific grant from funding agencies in the public, commercial, or not-for-profit sectors.

Data Availability Statement: The data sets used during current study are available from the corresponding author on reasonable request.

Conflicts of Interest: The authors declare no conflict of interest.

\section{References}

1- El-Naggar: AK; Chan John, KC; Grandis, JR; Takata, T; Slootweg, PJ. World Health Organization Classification of Head and Neck Tumours. 4th ed. Lyon, France, W.H.O. 2017, p. 347. 
2- Junquera, L; Ascani, G; Vicente, JC; Consuegra, GL; Roig, P. Ameloblastoma revisited. Ann. Otol. Rhinol. Laryngol. 2003, 112, 1034- 39.

3- Slootweg, PJ. Odontogenic tumors- an update. Dent. Oral Pathol. 2016; 12: 1-9.

4- Roopa, SR; Dominic, A; Surendra, L; Aamir, MN; Bhaskar, N. A Histopathology-based Assessment of Biological Behavior in Oral Hyalinizing Odontogenic Tumors and Bone Lesions by Differential Stains. J. Cont. Dent. Prac. 2021, 22, 691-702.

5- Amr, AM; Zeinab, ED; Sahar, ME; Ibrahim, MZ. Expression of argyrophilic Nucleolar organizer regions counts and proliferating cell nuclear antigen in epithelial odontogenic tumors. Alex. Dent. J. 2019, 44, 22- 27.

6- Kumar, V; Uma, K; Soundarya, N; Sangeetha, R; Smitha, T. Comparative morphometric study of AgNORs in variants of ameloblastoma. J. Oral. Maxillofac. Pathol. 2012, 16, 354- 58.

7- Prasanna, MD; Charan, CR; Ealla, KK; Surekha, V; Kulkarni, G; Gokavarapu, S. Analysis of silver stained nucleolar organizing regions in odontogenic cysts and tumors. J. Oral. Maxillofac. Pathol. 2014, 18, 45- 48.

8- Weis, SM; Cheresh, DA. Tumor angiogenesis: molecular pathways and therapeutic targets. J. Nat. Med. 2011, 17, 1359- 70.

9- Hande, AH; Gadbail, AR; Sonone, AM; Chaudhary, MS, Wadhwan, V; Nikam A. Comparative analysis of tumour angiogenesis in solid multicystic and unicystic AM by using CD 105 (endoglin). Arch. Oral Biol. 2011, 56, 1635-40.

10- Gadbail, AR; Hande, AH; Chaudhary, MS; Gawande, M; Patil, S; Tekade, S; Gondivkar, S. Tumor angiogenesis in keratocystic odontogenic tumor assessed by using CD-105 antigen. J. Oral Pathol. Med. 2011, 40, 263-69.

11- Jamshidi, S; Zargaran, M; Baghaei, F; Shojaei, S; Zare Mahmoodabadi, R; Dehghan, A; Moghimbeigi, A. An immunohistochemical survey to evaluate the expression of CD105 and CD34 in AM and odontogenic keratocyst. J. Dent. (Shiraz). 2014, 15, 192-98.

12- Astekar, M; Joshi, A; Ramesh, G; Metgud, R. Expression of vascular endothelial growth factor and microvessels density in oral tumorigenesis. J. Oral Maxillofac. Pathol. 2012, 16, 22- 26.

13- Mulazim, HB; Shahida, N; Saeed, AK; Hashmi, I; Perveen, S; Qureshi, SS; Chaudhry, NA; Qureshi, GR; Hasan, M. Modified method of AgNOR staining for tissue and interpretation in histopathology. Int. J Exp. Path. 2007, 88, 47-53.

14- Khurshid, A; Sultan, ZK; Nuzhat, S; Alghamdi, O; Muhammad, S; Mokeem, S; Ali, S; Abduljabbar, T; Vohra, F. Assessment of tumor angiogenesis by expression of CD 105 in ameloblastoma, odontogenic keratocyst and central giant cell lesion. Asian Pac. J Cancer Prev. 2020, 21, 3373-79.

15- Romero, L; Aguiar, B; Alfaro, E; Porcayo, M; Porcayo, A; Vejar, V; Maldonado, ER. AgNOR Polymorphism associated with squamous intraepithelial lesions and invasive carcinoma with HPV infection. J. Salud. Publica. Mex. 2009, 51, 134- 40.

16- Weidner, N; Carroll, PR; Flax, J; Blumenfeld, W; Folkman, J. Tumor angiogenesis correlates with metastasis in invasive prostate carcinoma. Am. J. Pathol. 1993, 143,401-02.

17- Chen, Y; Wang, JM; Li, TJ. Ameloblastic fibroma: a review of published studies with special reference to its nature and biological behavior. Oral Oncol. 2007, 43, 960- 69.

18- Hanemann, JA; Miyazawa, M; Souza, MS. Histologic grading and nucleolar organizer regions in oral squamous cell carcinomas. J. Appl. Oral Sci. 2011, 19, 280-85.

19- Alaeddini, M; Khalili, M; Tirgari, F; Etemad, S. Argyrophilic proteins of nucleolar organizer regions (AgNORs) in salivary gland mucoepidermoid carcinoma and its relation to histological grade. Oral Surg. Oral Med. Oral Pathol. Oral Radiol. 2008, 6, 758-62.

20- Carnelio, S; Vij, H. Expression of tenascin and nucleolar organizer region in ameloblastoma and ameloblastic fibroma. J. Oral. Pathol. Med. 2010, 39, 223- 29.

21- Nidhi, G; Ahmed, M; B, R; Kiran, J. Proliferative assessment using AgNORs in Dentigerous cyst, Keratocystic odontogenic tumor, unicystic ameloblastoma and multicystic ameloblastoma. Inter. J. of curr. res. 2017, 12, 23-28.

22- Seifi, S; Shafaie, S; Ghadiri, S. Microvessel density in follicular cysts, keratocystic odontogenic tumors and ameloblastomas. Asian. Pac. J. Cancer. Prev. 2011, 12, 351- 56.

23- Martano, M; Restucci, B; Ceccarelli, DM; Muzio, LL; Maiolino, P. Immunohistochemical expression of vascular endothelial growth factor in canine oral squamous cell carcinomas. Oncol. Lett. 2016, 11, 399-404.

24- Liu, DX; Doyle, LA; Bouljihad, MT; Didier, PJ; Gilbert, MH; Wang X, Pahar, B; Bohm, RP; Veazey, RS; Lackner, AA. Locally infiltrative ameloblastic fibroma in a rhesus macaque (Macaca mulatta) with characterizations of its proliferating activity and biological behavior. J. Vet. Diagn. Invest. 2012, 24, 630- 35 . 